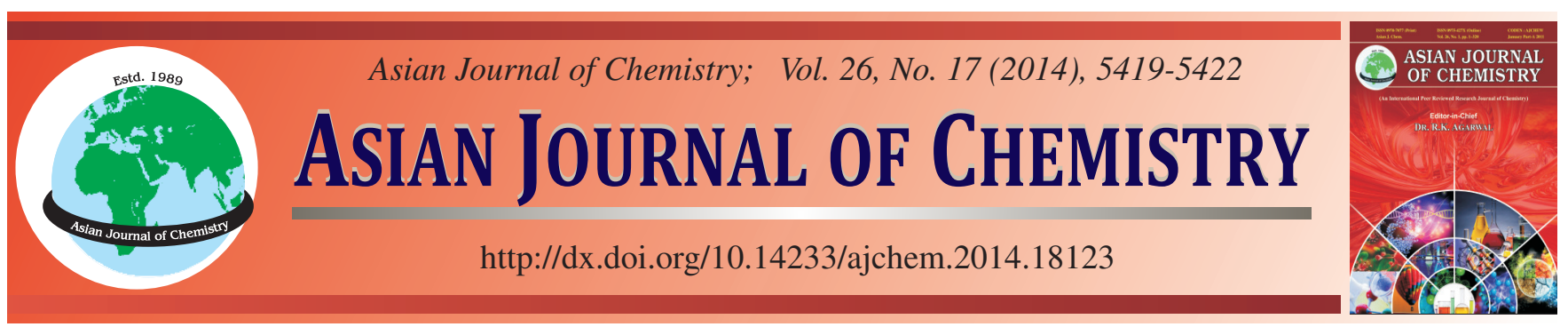

\title{
Electrical Properties of Composite Polyaniline/Superconducting Ceramic: Polyaniline/Neodymium-Barium-Copper Oxide $\dagger$
}

\author{
J.P. Fernandes ${ }^{1}$, G.W. Duarte ${ }^{1}$, C. Caldart $^{2}$, J.M.M. De Mello ${ }^{2,3}$, J. Dal Magro ${ }^{2,3}$, H.G. Riella ${ }^{2, *}$ and M.A. Fiori ${ }^{2,3, *}$
}

${ }^{1}$ Post-Graduation Program in Chemical Engineering. Universidade Federal da Santa Catarina - Florianópolis, 88040-900 -SC, Brazil ${ }^{2}$ Post-Graduation Program in Environmental Science, Universidade Comunitária da Região de Chapecó (UNOCHAPECO)-Chapecó, 89809000-SC, Brazil

${ }^{3}$ Post-Graduation Program in Technology and Management of the Innovation. Universidade Comunitária da Região de Chapecó (UNOCHAPECO) - Chapecó, 89809-000-SC, Brazil

${ }^{4}$ Laboratory of Advanced Materials and Processes - LMPP. Universidade do Extremo Sul Catarinense/iParque/UNESC-Criciúma, 88806-000SC, Brazil

*Corresponding authors: E-mail: riella@enq.ufsc.br; fiori@unochapeco.edu

\begin{abstract}
Polyaniline (PANI) is one of the most attractive conductor polymers due to its high conductivity, chemical stability and easy polymerization. Polyaniline can be applied to actuators, super-capacitors, electromagnetic devices and especially gas sensors. The neodymium-bariumcopper ceramic, produced by oxide compounds (NBCo), is a special ceramic material that can be used as superconductive material at relatively high temperatures, depending on the treatment that it is submitted during its synthesis. Therefore, the union of these two materials creates a versatile composite. This study evaluated the electrical properties of NBCo composites in a polymeric matrix of polyaniline at high temperatures. The parameters evaluated were the particle size, percentage of NBCo in the polymeric matrix and the composite temperature. The results showed that the conductivity is dependent on the particle size, percentage of NBCo and temperature. An increase in the temperature, in the particle size of NBCo compound and a decrease of NBCo percentage in the polyaniline matrix contribute to increase the electrical conductivity of the composite. The curve of current versus electric potential showed a non-Ohmic behavoiur for all compositions and testing conditions.
\end{abstract}

Keywords: Polyaniline polymer composites, Neodymium-barium-copper oxides, Superconducting ceramics and conducting polymers.

\section{INTRODUCTION}

A special family of ceramics that shows great potential to be used in the development of conductive elements with high degradation resistance, are known as $\mathrm{REBCO}(\mathrm{RE}=$ rare-earth, $\mathrm{B}=$ barium, $\mathrm{C}=$ copper, $\mathrm{O}=$ oxygen). These materials are produced with metal oxides alloy, pressed and heated at high temperatures to accelerate the process of atomic diffusion ${ }^{1-4}$.

These kind of ceramics are often applied in electronic industries. When produced with special chemical elements and at special physical conditions, these materials present interesting electrical and thermal properties. Some special ceramics have superconducting properties at low temperatures and other ones are applied as deformation sensor systems. Neodymiumbarium-copper (NBCo) is a special ceramic that presents high conductivity at low temperatures and is produced by oxide compounds, i.e., neodymium oxide, barium oxide and copper oxide. Many papers have been published just citing this as a ceramic superconductor without further regard to its conductivity at ambient temperatures ${ }^{5-8}$.

The scientific community has studied these conducting polymer materials extensively. Organic proton conductors, mainly polymers, are promising, low cost materials and have been studied as components in sensors, electrochromic devices, batteries, biomimetic sensors, robotic actuators and artificial muscles ${ }^{9}$. In general, as proton conductors show an electrical conductivity that often depends on the relative humidity of the environment (RH \%), they are also studied as humidity sensors ${ }^{10}$.

Among the vast variety of conducting polymers with conjugated double bonds, a considerable interest has been shown toward polyaniline (PANI) due to its excellent redox reversibility and good chemical stability. In addition, polyaniline is easily synthesized by the electrochemical or chemical 
oxidation of the low-cost aniline monomer. However, it is rather difficult to make either films or coated layers from it because it is infusible and insoluble in the most common solvents. Therefore, its use in the above-mentioned commercial applications has been limited ${ }^{11}$.

Polyaniline/metal nano-particle composites have been the subject of numerous studies due to their potential applications in electrocatalysis, chemical sensing and protective coatings against corrosion $^{12}$.

Therefore, the combination of the electrical characteristics of this special ceramic at low temperatures and polyaniline at high temperatures make this composite a material with good electrical properties and chemical stability over a large temperature range.

\section{EXPERIMENTAL}

Synthesis of polyaniline: Polyaniline was synthesized using ammonium persulphate as oxidizing agent in the presence of an aqueous solution of $\mathrm{HCl}$.

Previously, $80 \mathrm{~mL}$ of $1 \mathrm{M} \mathrm{HCl}$ aqueous solution was prepared and cooled to $10{ }^{\circ} \mathrm{C}$. To proceed with the synthesis other two solutions were prepared using the $1 \mathrm{M} \mathrm{HCl}$ aqueous solution as reaction medium. The first solution prepared contained $0.0222 \mathrm{~mol}(2 \mathrm{~mL})$ of the monomer aniline dissolved in $51.1 \mathrm{~mL}$ of $1 \mathrm{M} \mathrm{HCl}$ aqueous solution. This solution was maintained under continuous stirring. The second solution containing ammonium persulphate $(5.11 \mathrm{~g})$ was also dissolved in $25.6 \mathrm{~mL}$ of precooled $1 \mathrm{M} \mathrm{HCl}$. The ammonium persulphate solution was then added dropwise to the aniline solution for about $0.5 \mathrm{~h}$. Ammonium persulphate was added slowly because the reaction is very exothermic and the temperature of $10^{\circ} \mathrm{C}$ needs to be maintained during the entire process. The mixture was allowed to react for $2 \mathrm{~h}$ under continuous stirring and with controlled temperature. A dark green polyaniline precipitated was obtained. The precipitated polyaniline was filtrated and consecutively washed with distilled water in order to remove unreacted salts. Subsequently, it was dried at $120.0^{\circ} \mathrm{C}$ for $2 \mathrm{~h}$.

Polyaniline/NBCo preparations: Polyaniline/NBCo composite was prepared by mechanically mixing NBCo and polyaniline. The NBCo and polyaniline were submitted to mixture processing for $2 \mathrm{~h}$ in a mechanical homogenizing system at room temperature and a constant velocity of $10 \mathrm{rpm}$.

The particle sizes of the NBCo used were 50, 100 and 150 $\mu \mathrm{m}$. The concentration of NBCo used were 10.0, 30.0 and 50.0 wt $\%$. After being mixed with the polyaniline, the cylindrical samples were compacted with a pressure of $312.5 \mathrm{kgf} / \mathrm{cm}^{2}$. Two standard samples were also used to better explain the results obtained. This samples consist in: one with $0 \%$ of NBCo $(100 \%$ polyaniline) other with $100 \%$ of NBCo ( $0 \%$ polyaniline).

To study the statistical significance of the particle size, temperature and percentage of the NBCo in the polyaniline matrix, an experimental factorial planning was adopted (Table-1).

To evaluate the effect of temperature in the electrical property of polyaniline/NBCo composite, the samples obtained in the planning were submitted to heating or cooling in a chamber with controlled atmosphere. The temperature values used in this work were $-25.0,0.0,25.0$ and $50.0^{\circ} \mathrm{C}$.

\begin{tabular}{ccc} 
& \multicolumn{2}{c}{ TABLE-1 } \\
& EXPERIMENTAL FACTORIAL PLANNING \\
\hline Sample & Particle size of NBCo $(\mu \mathrm{m})$ & Concentration of NBCo $(\%)$ \\
\hline 1 & 50 & 10 \\
2 & 150 & 10 \\
3 & 50 & 50 \\
4 & 150 & 50 \\
5 & 100 & 30 \\
6 & 100 & 30 \\
7 & 100 & 30 \\
\hline
\end{tabular}

Microscopic characterization and electrical measurements: It was used the technique of scanning electron microscopy (SEM) to characterize the polyaniline/NBCo composite. The SEM experiments were carried out in a JEOL JSM-6390LV apparatus with $15 \mathrm{kV}$.

To determine the electrical conductivity, the four-probe method was applied. This procedure was carried out for all samples of polyaniline/NBCo. The electrical measurements on the composite samples were performed in triplicate for different polarization configurations: $0.50,1.00,1.50,2.00$, $2.50,3.00,3.50,4.00,4.50$ and $5.00 \mathrm{~V}$. The I-E curve was taken with brass surfaces, keeping maximum contact on the sides of the sample.

\section{RESULTS AND DISCUSSION}

Fig. 1 demonstrates the dependence of the electrical conductivity of the composite on the temperature for different particle size of NBCo with constant concentration of $10 \%$ of NBCo in the in the polyaniline matrix.

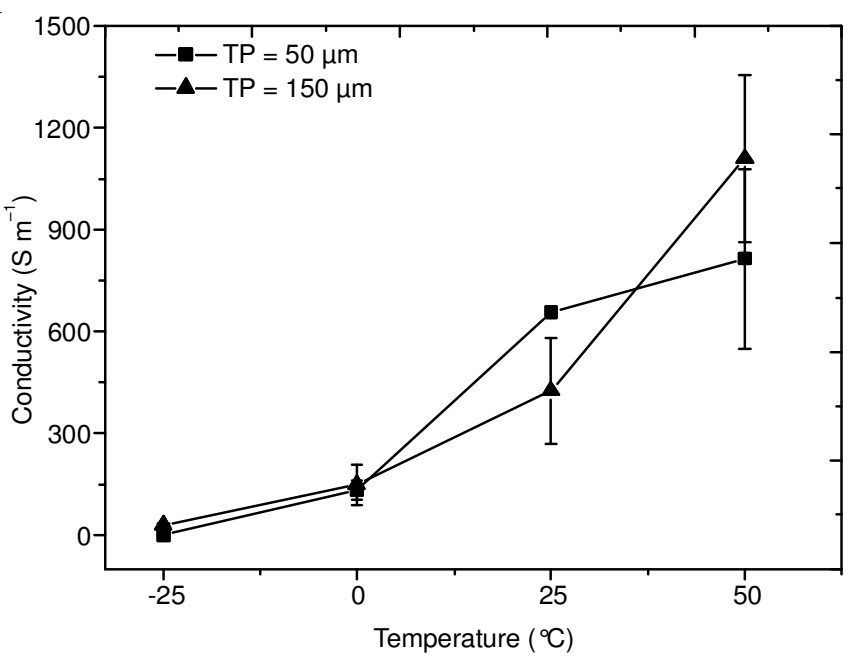

Fig. 1. Electrical conductivity of the composite as a function of temperature for the different particle sizes of the NBCo compound in the polyaniline matrix

The electrical conductivity of the polyaniline/NBCo composite depends strongly on the temperature. The increase of the sample temperature promotes the increase of electrical conductivity in all NBCo samples. It was observed that at low temperatures $\left(\mathrm{T}<0{ }^{\circ} \mathrm{C}\right)$, the conductivity of the composite did not show significant variation. These results indicate that the conduction mechanisms present in the composite are positively affected by an increase of thermal energy. Mzenda et al. ${ }^{12}$ reported that the electrical conduction mechanisms in polyaniline polymer are dependent on the thermal energy of 
the system. A reduction in the temperature causes a decrease in the mobility of charge carriers in its structure and, consequently, a reduction of the electrical conductivity values ${ }^{12}$. Therefore, the results indicate that the predominant electrical conduction mechanism in the polyaniline/NBCo composite is the electrical conduction mechanism existing in the polyaniline phases and the particle size does not affect the electrical property as significant as the polyaniline phase change.

Fig. 2 shows the dependence of the electrical conductivity of the composite on temperature for different percentages of the NBCo compound with a constant particle size of $50 \mu \mathrm{m}$ in the polyaniline matrix.

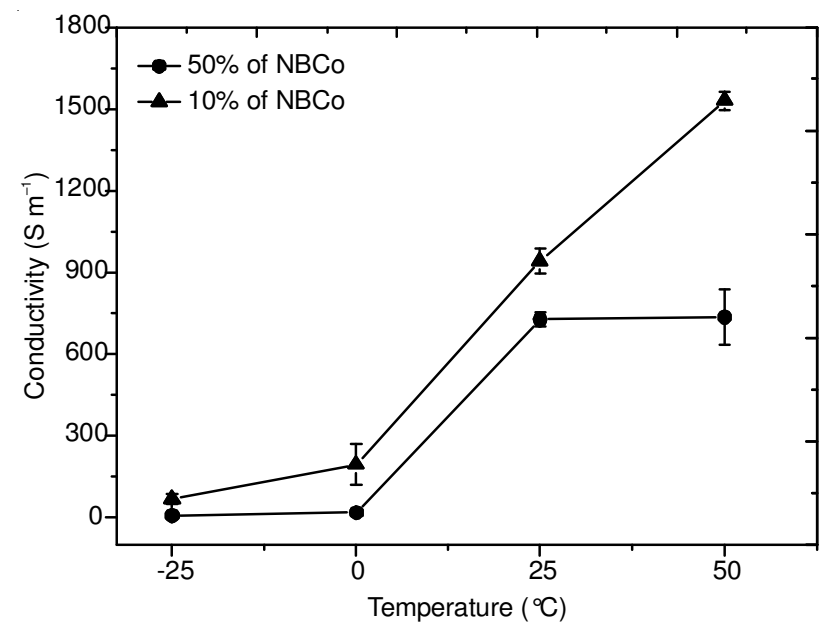

Fig. 2. Electrical conductivity of the composite as a function of temperature for different percentages of the NBCo compound in the polyaniline matrix

An increase in the particle size of the NBCo compound and a decrease of the NBCo percentage in the polyaniline matrix contribute to an increase in the electrical conductivity of the composite, but do not modify the thermal comportment of the electrical conduction mechanism in the composite.

These results show a possible effect of the temperature, percentage and particle size of the NBCo in the composite on the electrical conductivity. Table-2 shows the variance analysis (ANOVA) for the electrical conductivity values obtained with different temperature values, particle sizes and percentage of NBCo and also with different electrical polarization.

The ANOVA results indicate that the particle size and percentage of the NBCo in the composite and the sample temperature are significant factors in the electrical conductivity of the polyaniline/NBCo composite. The statistically estimated effects confirm a positive effect for the sample temperature and particle size of NBCo compound and a negative effect for the percentage of NBCo in the polyaniline matrix. So, by statistically estimated values, it is possible to present a statistical relation between the polyaniline/NBCo conductivity and the significant factors as in eqn. 1.

$\sigma(\mathrm{C} \%, \mathrm{~T}, \mathrm{TP})=587,39( \pm 82,04)-240,72( \pm 96,20) . \mathrm{C} \%+$ $499,53( \pm 96,21) . \mathrm{T}+343,77( \pm 96,21) \cdot \mathrm{TP}$

These statistical results confirm that a decrease in the quantity of polyaniline phases in the composite, by increasing the percentage of the NBCo, promotes a reduction in the electrical conductivity.

Fig. 3 shows the dependence of the electrical conductivity of the composite on the percentage of NBCo with different particle sizes. Through graphical analysis, it can be noted that the increasing the amount of NBCo promotes a decrease in electrical conductivity of the composite. The dispersion of NBCo phases in the polyaniline matrix causes a reduction in the mean free path of the charge carriers from the polyaniline phases and generates failures in the composite matrix. Consequently, the electrical conductivity of the polyaniline/NBCo composite is reduced. This same property was observed for the polyaniline/NBCo composite obtained with different particle sizes of NBCo.

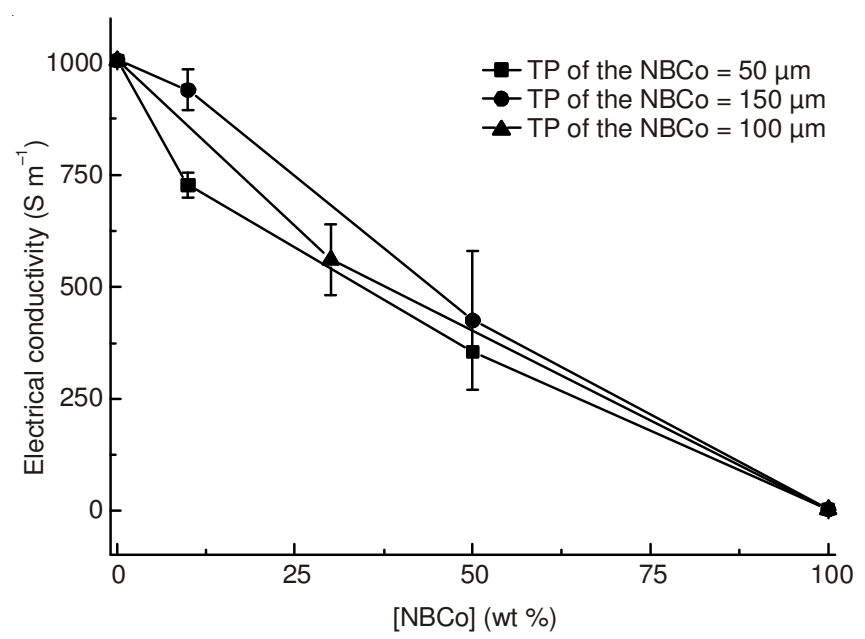

Fig. 3. Dependence of the electrical conductivity of the composite polyaniline/NBCo on the percentage of NBCo in the composite with different particle sizes

Fig. 4 shows the SEM images of the polyaniline/NBCo composite obtained with $50 \mathrm{wt} \%$ of NBCo in the polyaniline matrix with different NBCo particle sizes. Fig. 4a shows the composite obtained with a particle size of $50 \mu \mathrm{m}$. The images present the formation of grains with different sizes distributed

TABLE-2

VARIANCE ANALYSIS (ANOVA) FOR THE ELECTRICAL CONDUCTIVITY VALUES OBTAINED WITH DIFFERENT TEMPERATURE VALUES, PARTICLE SIZES AND PERCENTAGE OF NBCo AND WITH DIFFERENT ELECTRICAL POLARIZATION

\begin{tabular}{|c|c|c|c|c|c|}
\hline Factor & SS & $\mathrm{df}$ & MS & F & $\mathrm{p}$ \\
\hline $\mathrm{C} \%$ & *1390691.9 & 1 & 1390691.9 & 6.26 & 0.01846 \\
\hline $\mathrm{T}$ & *5988651.1 & 1 & 5988651.1 & 26.96 & 0.00002 \\
\hline$P$ & 66115.09 & 1 & 66115.09 & 0.30 & 0.58970 \\
\hline $\mathrm{TP}$ & *2836303.63 & 1 & 2836303.63 & 12.77 & 0.00130 \\
\hline Error & 6220128.15 & 28 & 222147.43 & - & - \\
\hline TOTAL SS & 16501889.83 & 32 & 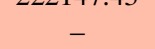 & - & - \\
\hline
\end{tabular}

*Significant variables. (C \%): NBCo percentage; (T): sample temperature; (P): Electrical potential applied and (TP): NBCo particle size. 
throughout the composite matrix, formatting irregular regions and thus hindering the electrical conduction. Fig. $4 \mathrm{~b}$ shows larger regular regions along the composite obtained with an NBCo particle size of $150 \mu \mathrm{m}$. It is evident that the number of failures was reduced in the composite with larger NBCo particle sizes and consequently the electrical conductivity of this composition is higher than the composite obtained with a particle size of $50 \mu \mathrm{m}$.
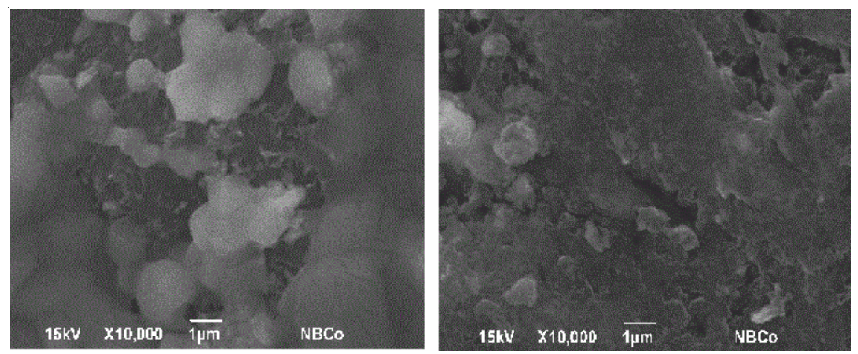

Fig. 4. SEM images of the polyaniline/NBCo composite obtained with 50 wt $\%$ of NBCo in the polyaniline matrix with different NBCo particle sizes: (a) grain of the composite and (b) regular regions along the composite obtained with an NBCo particle size of $50 \mu \mathrm{m}$

The characterization by SEM reveals a biphasic structure with good interaction between the NBCo ceramic superconductor particles and the polyaniline polymeric matrix. Small particles of NBCo increase the number of interfaces, which act as scattering centers for the charge carriers in the composite.

Fig. 5a and 5b shows the I-E curves (electrical current versus electrical potential) for polyaniline/NBCo composites with 10 wt $\%$ NBCo and 50 wt \% NBCo, respectively. I-E electrical characterizations were realized at different temperatures.

I-E curves show a nonlinear increase in the electrical current, with the increase in the applied electrical voltage for all temperature conditions. This property corroborates with the presence of a dominant non-Ohmic electrical conduction mechanism in the polyaniline/NBCo composite. It also shows that the dominant electrical conduction mechanism favours an increase in the thermal energy of the system.

Nevertheless, it appears that increasing the percentage of NBCo promotes an increase in electrical resistance of the composite. As already mentioned above, NBCo particles are barriers to the movement of charge carriers in polyaniline phases, which are responsible for the dominant electrical conduction mechanisms in the polyaniline/NBCo composite.

\section{Conclusion}

Within four analyzed factors at work, only electrical polarization does not affect the electrical conductivity of the polyaniline/NBCo composite. These statistical results indicated that an increase in temperature and particle size influences electrical conductivity of the composite positively while an increasing percentage of NBCo influences it negatively. Electrical characterization showed the the dominant electrical conduction mechanism is non-Ohmic and positively dependent on the temperature. This demonstrate that the dominant electrical conduction mechanism in polyaniline/NBCo composite is relative to polyaniline phases.
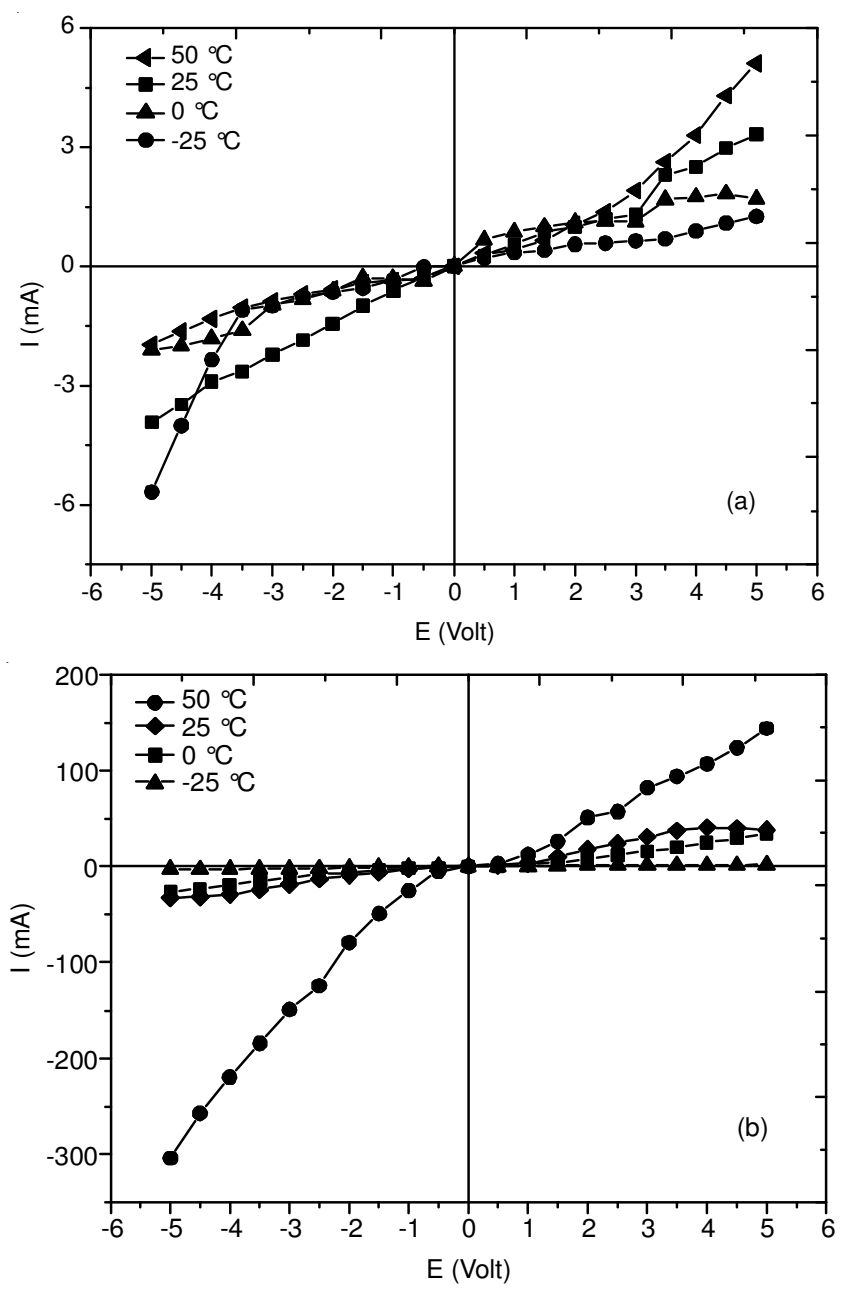

Fig. 5. I-E Curve of polyaniline/NBCo composite. (a) $10 \mathrm{wt} \% \mathrm{NBCo}$ and (b) $50 \mathrm{wt} \% \mathrm{NBCo}$

\section{ACKNOWLEDGEMENTS}

The authors thank the Laboratory of the Microscopy (LCME) of the Universidade Federal de Santa Catarina-UFSC and National Council for Scientific and Technological Development - CNPq for the financial support of the work.

\section{REFERENCES}

1. S. Bhadrakumari and P. Predeep, Eur. Polym. J., 45, 226 (2009).

2. H.A. Blackstead, J.D. Dow and M. Lehmann, Solid State Commun., 107, 323 (1998).

3. Y. Li, S. Han, J. Li, X. Zhu and L. Hu, J. Alloys Comp., 458, 357 (2008).

4. J. Valo, M. Leskelä, B.C. Hauback, H. Fjellvåg, S.-M. Koo and K.V. Rao, Int. J. Inorg. Mater, 2, 269 (2000).

5. N. Hari Babu, K. Iida, Y. Shi and D.A. Cardwell, Physica C, 445-448, 286 (2006)

6. H. Fujimoto and H. Ozaku, Physica C, 412-414, 657 (2004).

7. W.H. Tang and J. Gao, Physica C, 298, 66 (1998).

8. D.H. Ha, Physica C, 302, 299 (1998).

9. M. Shahinpoor, Electrochim. Acta, 48, 2343 (2003).

10. G. Casalbore-Miceli, N. Camaioni, M.J. Yangh, M. Zhen, W.X. Zhanb and A. D'Aprano, Solid State Ion., 100, 217 (1997).

11. M.S. Cho, S.Y. Park, J.Y. Hwang and H.J. Choi, Mater. Sci. Eng. C, 24, 15 (2004).

12. V.M. Mzenda, S.A. Goodman, F.D. Auret and L.C. Prinsloo, Synth. Met., 127, 279 (2002). 